\title{
THE EFFECT OF SMOKING ON SURVIVAL AND BONE LOSS OF IMPLANTS WITH A FLUORIDE- MODIFIED SURFACE: A 2-YEAR RETROSPECTIVE ANALYSIS OF 1106 IMPLANTS PLACED IN DAILY PRACTICE.
}

\author{
Stijn Vervaeke, Bruno Collaert, Stefan Vandeweghe, Jan Cosyn, Ellen Deschepper \& Hugo De \\ Bruyn
}

\begin{abstract}
Aim: To compare survival and peri-implant bone loss of implants with a fluoride-modified surface in smokers and nonsmokers.
\end{abstract}

Materials and Methods: Patient files of all patients referred for implant treatment from November 2004 to 2007 were scrutinized. All implants were placed by the same experienced surgeon (BC). The only inclusion criterion was a follow-up time of at least 2 years. Implant survival and bone loss were assessed by an external calibrated examiner (SV) comparing digital peri-apical radiographs taken during recall visits with the postoperative ones. Implant success was determined according to the international success criteria (Albrektsson et al. 1986). Survival of implants installed in smokers and nonsmokers were compared using the log-rank test. Both non-parametric tests and fixed model analysis were adopted to evaluate bone loss in smokers and nonsmokers.

Results: 1106 implants in 300 patients (186 females; 114 males) with a mean follow-up of 31 months (SD 7.15; range 24-58) were included. 19 implants in 17 patients failed, resulting in an overall survival rate of $98.3 \%$ on implant level and $94.6 \%$ on patient level. After a follow-up period of 2 years, the CSR was $96.7 \%$ and $99.1 \%$ with the patient and implant as statistical unit respectively. Implant survival was significantly higher for nonsmokers compared to smokers (implant level $p=0.025$; patient level $p=0.017$ ). The overall mean bone loss was 0.34 $\mathrm{mm}(\mathrm{n}=1076$; SD 0.65; range 0.00-7.10). Smokers lost significantly more bone compared to nonsmokers in the maxilla $(0.74 \mathrm{~mm}$; SD 1.07 vs $0.33 \mathrm{~mm}$; SD 0.65; $\mathrm{p}<0.001)$, but not in the mandible $(0.25 \mathrm{~mm}$; SD 0.65 vs $0.22 \mathrm{~mm} ; \mathrm{SD} 0.50 ; \mathrm{p}=0.298)$.

Conclusion: The present study is the first to compare peri-implant bone loss in smokers and nonsmokers from the time of implant insertion (baseline) to at least 2 years of follow-up. Implants with a fluoride-modified surface demonstrated a high survival rate and limited bone loss. However, smokers are at higher risk to experience implant failure and more prone to show peri-implant bone loss in the maxilla. Whether this bone loss is predicting future biological complications remains to be evaluated.

\section{INTRODUCTION}


Smoking is harmful for general health and has been associated with various diseases, such as cardiovascular diseases, cancer and respiratory diseases (Fielding et al. 1985; La Vecchia et al. 1991; Peto et al. 1996; Millar \& Locker 2007).

Also, the usage of tobacco has an overwhelming impact on oral health and is associated with tooth loss, loss of attachment, vertical bone loss, dry socket and impaired wound healing after surgery (Meechan et al. 1988; Johnson \& Bain 2000; Kornman \& Robertson 2000; Scabbia et al. 2001; Baljoon et al. 2004; Millar \& Locker 2007; Warnakulasuriya et al. 2010). Although the mechanisms are not fully understood, wound healing is disturbed due to an impaired fibroblast function, less collagen production, an impaired vasculature affecting revascularization after surgery and an impaired polymorphonuclear neutrophilic and macrophagal function (Kenney et al. 1977; MacFarlane et al. 1992; Jorgensen et al. 1998; Lehr 2000; Palmer et al. 2005).

Smoking is also known to affect the outcome of implant treatment. Several studies reported lower survival rates for implants installed in smokers (Bain \& Moy 1993; Schwartz-Arad et al. 2002; Nitzan et al. 2005; Moy et al. 2005; Strietzel et al. 2007; Koldsland et al. 2009; Anner et al. 2010). Some studies show that especially the maxilla is more prone to implant failure (De Bruyn \& Collaert 1994). Most of these are early failures and occur before functional loading (De Bruyn \& Collaert 1994; Gorman et al. 1994; Lambert et al. 2000).

Only a limited number of studies, summarized in Table 1, have compared peri-implant bone loss in smokers and nonsmokers. Only 1 study failed to show a significant difference (Aalam \& Nowzari 2005). The other 15 reported significantly better peri-implant bone levels in nonsmokers compared to smokers (Haas et al. 1996; Lindquist et al. 1996; Lindquist et al. 1997; Carlsson et al 2000; Feloutzis et al. 2003; Karoussis et al. 2004; Penarrocha et al. 2004; Wennström et al. 2004a; Wennström et al. 2004b; Galindo-Moreno et al. 2005; Nitzan et al. 2005; Schwartz-Arad et al. 2005; DeLuca \& Zarb 2006; Levin et al. 2008; Vandeweghe et al. 2009).

The last decade, most of the implant companies changed the implant surface to a moderately rough surface in order to enhance the osseointegration process. Fluoride-

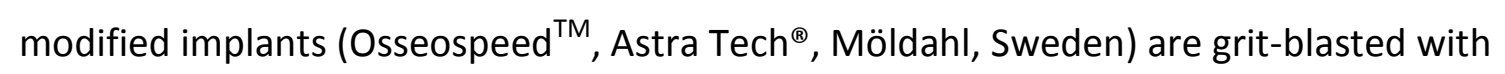
titanium dioxide particles followed by an additional treatment with diluted fluoride acid, which results in a nanoscale surface topography (Ellingsen et al. 2004). Results from 
experimental studies suggest that osseointegration is enhanced around fluoride-modified implant surfaces, especially during the first weeks of healing (Ellingsen et al.2004; Cooper et al. 2006; Berglundh et al. 2007). Enhanced osteoblast differentiation (Masaki et al. 2005; Isa et al. 2006; Cooper et al. 2006; Stanford et al. 2006; Guo et al. 2007), platelet activation and thrombogenic properties (Stanford et al. 2006; Thor et al. 2007) of the fluoride-modified surface have been reported. A recent comparative study shows that, despite smoking having an adverse effect on peri-implant bone healing, surface topography changes may affect bone-to-implant contact (d'Avila et al. 2010). This might have an effect on peri-implant bone preservation and thus on the long-term success of dental implants.

The aim of this study was to evaluate implant survival and peri-implant bone loss of implants with a fluoride-modified surface with respect to self-reported smoking habits.

\section{MATERIALS \& METHODS}

\section{Patient Selection and Clinical procedures}

All patients referred for implant treatment between November 2004 and 2007 were scrutinized. Patients were asked for smoking habits as part of the medical anamnesis during intake. The only inclusion criterion was a follow-up time of at least 2 years. All implants were placed by the same experienced surgeon $(B C)$ in healed ridges. In case of previous tooth extraction a healing time of at least 3 months was respected before implant insertion. $A$ crestal incision was made in order to raise the flap and implants were installed according to the manufacturer's guidelines. Digital peri-apical radiographs were taken by the surgeon immediately after implant insertion (baseline) with commercially available filmholders using the parallel long-cone technique in order to visualize the implant threads and marginal boneto-implant contact level. Hence bone loss is reported from the time of surgery. After implant treatment all patients were scheduled for professional maintenance including radiographic follow-up. The frequency and content of professional maintenance was based on the clinical situation and adapted to the individual needs of the patients. Basically this implies a recall interval of 6 or 12 months during the first years. The final restorations were made by the referring dentist.

All implants with at least 2 years of follow-up and thus participating in the professional maintenance recall system were included to evaluate implant survival and peri-implant bone 
loss. An external examiner from the University of Ghent had access to the patient files. The study protocol was approved by the ethical committee of the Ghent University Hospital.

\section{Examination Criteria and Statistical analysis}

An Implant was considered a failure when it was removed because of implant mobility, loss of integration, ongoing bone loss, infection and/or persistent pain or patient discomfort (Zarb \& Albrektsson 1998). An individual implant was dichotomized as either survival (value 0) or a failure (value 1) for Kaplan-Meier survival analysis. The log rank test was used to compare implant survival in smokers and nonsmokers both with the patient and the implant as statistical unit. Peri-implant bone loss was assessed by an external examiner (SV) comparing peri-apical radiographs, taken during recall visits, with the post-operative ones taken by the surgeon immediately after implant insertion using digital software (Visi-Quick ${ }^{\circledR}$, Amsterdam, The Netherlands) with an accuracy of $0.1 \mathrm{~mm}$ (De Bruyn et al. 2008; Collaert \& De Bruyn. 2008). Care was taken to visualize the implant threads clearly. Marginal bone level was determined both at the mesial and distal site of each implant by measuring the distance between the reference point (lower border of the smooth implant collar or the uppermost point of the microthreaded part) and the marginal bone-to-implant contact (Figure 1). These values were averaged to obtain a single value per implant (individual implant bone loss = $\mathrm{IIBL})$. The reference point has been described by previous authors, using the same implant system (Åstrand et al. 2004, De Bruyn et al. 2008, Collaert \& De Bruyn 2008, Van de Velde et al. 2010). The patient's bone loss (PBL) was calculated as the mean value of all IIBL's.

Differences between smokers and nonsmokers were evaluated with the Mann-Whitney Utest. Moreover mixed model analysis was performed to analyze bone loss using PASW statistics 18 because of clustering of implants in patients and jaws. Therefore a logarithmic transformation of the data was performed to obtain linearity and homoskedasticity of the residuals. To evaluate the impact of time on bone loss, the Mann-Whitney U-test was adopted. Inter- and intra-examiner reliability was assessed using percent agreement within $0.2 \mathrm{~mm}$ deviation, Spearman correlation coefficient and the Wilcoxon signed ranks test. An individual implant was called a success when bone loss was $\leq 1.5 \mathrm{~mm}$ during the first year and $\leq 0.2 \mathrm{~mm}$ additionally per year (Albrektsson et al. 1986). The Fisher's exact test was used to compare success rates between smokers and nonsmokers. 


\section{RESULTS}

\section{IMPLANT SURVIVAL}

In total 300 patients, 186 females and 114 males, with 1106 implants were evaluated (Table 2). The mean age was 56 years (SD 12.05; range 17-82). Hundred-fifty-seven patients received implants in the maxilla and 143 in the mandible. Twenty-six of them received implants in both jaws. Out of 1106 implants, 121 implants supported single crowns, 318 supported fixed partial dentures, 631 supported fixed cross-arch bridges and 18 supported overdentures. An overview of implant length and diameter is shown in table 3.

After a mean follow-up period of 31 months (SD 7.15; range 24-58), 19 implants failed (1.7\%), resulting in an absolute survival rate of $98.3 \%$. Nine failures occurred before prosthetic loading. In total, 17 patients out of 300 (5.6\%) experienced implant failure. Table 4 shows cumulative survival rates (CSR). After a follow-up period of 2 years, the CSR was $96.7 \%$ and $99.1 \%$ with the patient and implant as statistical unit respectively.

Of 244 implants installed in 60 smokers, 8 implants (3.3\%) failed; of 849 implants installed in 235 nonsmokers, 11 implants failed (1.3\%) and of 5 patients with 13 implants, the smoking status was seemingly by mistake not registered into the patient record. In the smokers group, $1 / 139(0.7 \%)$ implant failed in the maxilla, whereas $7 / 105(6.7 \%)$ implants failed in the mandible. In the nonsmoking group, 4/502 (0.8\%) implants failed in the maxilla and 7/347 $(2.0 \%)$ in the mandible.

In smokers, the mandible was significantly more prone to implant loss compared to the maxilla $(p=0.012)$. This difference could not be found in nonsmokers $(p=0.085)$. Seven out of 60 smokers (11.7\%) and 10 out of 235 nonsmokers (4.3\%) experienced implant failure. In detail analysis showed a significant difference comparing smokers and nonsmokers for cumulative failure rates both on patient $(p=0.017)$ (Figure 2 ) and implant level ( $p=0.025$ ) (Figure 3). Table 5 shows that individual cumulative implant failure rates in smokers affect only the maxilla. Patient cumulative failure rates were not affected by jaw location.

\section{PERI-IMPLANT BONE LOSS}

Out of 1087 surviving implants, 1076 implants in 295 patients had readable radiographs and a follow-up of at least 2 years (Table 2). Intra-examiner repeatability on bone loss was high (95\% agreement within $0.2 \mathrm{~mm}$ deviation; Spearman correlation coefficient 0.925, p < 0.05 ; 
Wilcoxon signed ranks test $p=0.673$ ) as was the inter-examiner variability (90\% agreement within $0.2 \mathrm{~mm}$ of deviation; Spearman correlation coefficient $0.912, \mathrm{p}<0.05$; Wilcoxon signed ranks test $p=0.532$ ). After a mean follow-up of 31 months, the overall mean bone loss was $0.34 \mathrm{~mm}$ (SD 0.65; range: $0.00-7.10$ ) and $0.33 \mathrm{~mm}$ (SD 0.54; range: $0.00-4.90$ ) with the implant and patient as statistical unit respectively. Follow-up time of the individual implants did not influence peri-implant bone level changes $(p=0.084)$. An overview of bone loss values is given in Table 6. Individual Implants installed in smokers are significantly more prone to experience peri-implant bone loss compared to nonsmokers $(p<0.001)$ (Figure 4) with a significant difference for the maxilla $(p<0.001)$, but not for the mandible $(p=0,298)$ (Figure 5).

Implants installed in the maxilla lost significantly more bone compared with those in the mandible both for smokers $(p<0.001)$ and non-smokers $(p<0.001)$. The same is valid when the patient's bone loss was considered as statistical unit (Table 6).

This was confirmed after a logarithmic transformation of the data and fixed model analysis to correct for clustering of implants in patients and jaws. Results are given in Table 7.

\section{IMPLANT SUCCESS}

Individual implant success was calculated with respect to the follow-up time. The overall success rate, based on radiographs taken between 24 and 58 months after implant insertion was $95.0 \%$. A significant difference was found between smokers (89.6\%) and nonsmokers $(96.5 \%)(p<0.001)$. Table 8 gives an overview of success rates for smokers and nonsmokers with respect to the jaw. In the maxilla, the success rate was significantly higher for nonsmokers $(96.8 \%)$ compared to smokers $(87.8 \%)(p<0.001)$. This difference could not be found in the mandible ( $96.2 \%$ vs $92.2 \% ; p=0.083)$.

If a threshold of $<1 \mathrm{~mm}$ or $<2 \mathrm{~mm}$ of bone loss is accepted as the criterion for success, an overall success rate of $90.6 \%$ and $95.7 \%$ was found respectively.

\section{DISCUSSION}

This study scrutinized implant outcome in relation to smoking. Given the retrospective study design it is based on patient's records. As such it relies upon the accuracy of the record and the self-reported smoking habits of the patients. It is known from clinical studies relating 
general health issues with smoking, that patients cannot be considered truthful. Some patients considerably underreport their smoking behaviour (Kandell et al.2006; Attebring et al. 2001) and biochemical techniques are necessary to objectively quantify tobacco usage. Therefore a patient was called a smoker when it was written down in the patient file, irrespective of the amount of cigarettes consumed on a daily basis. As such, the study makes no distinction between heavy or light smokers. Also tobacco usage may change over time, but we consider smoking at the time of surgery as the decisive factor influencing periimplant bone and soft tissue healing.

Only a few clinical studies (Donati et al. 2008; Stanford et al. 2008; Toljanic et al. 2008) or abstracts (Steveling et al. 2009; Roediger et al. 2009) are available on implants with a fluoride-modified surface, showing an implant survival of $94.5 \%-100 \%$. Grit-blasted implants without the additional fluoride modification (TiOblast ${ }^{\mathrm{TM}}$ ) are well documented and show good clinical results with survival rates from 89.7 \% -100 \% (Cooper et al. 2008; Collaert \& De Bruyn. 2008; De Bruyn et al. 2008; Al-Nawas et al. 2010). The present study reports an absolute survival rate of $98.3 \%$ after $24-58$ months of follow-up, confirming the good results of the aforementioned studies. The cumulative survival calculation shows that the majority of the failures occur prior to prosthetic loading, although additional failures do occur after 2 years. Controlled long-term clinical trials to give insight in stability and prognosis of these novel implant surfaces are still lacking. Additionally this study reflects the everyday clinical practice were all implants, placed by one experienced clinician, are included.

The present study shows that smokers are 2.5 times more likely to experience implant failure, both on implant and patient level when comparing absolute survival rates. This is in accordance with a previous meta-analysis showing a risk of implant failure for smokers of 2.4 considering all included studies on implant-related data and 2.6 considering all included studies on patient-related data (Strietzel et al. 2007). Cumulative survival rates reveal a 4.0 and 3.3 times higher failure rate for smokers compared to nonsmokers on patient level and implant level respectively. In our analysis smokers showed significantly more implant failures in the mandible compared with the maxilla $(p=0.012)$. All of the failures in the mandible occurred in the posterior region. One could speculate that this may be caused by the high 
bone density and deficiency of vascularization known to occur in the posterior mandible, especially in elderly and edentulous patients. (Tolstunov 2007). This in combination with the negative effect of smoking on soft tissue healing due to an impaired revascularization may compromise bone healing after implant insertion, possibly increasing the number of early implant failures (Palmer et al. 2005). Additionally, negative effects of smoking on bone metabolism and delayed fracture healing are common sense in orthopaedics (Hoogendoorn et al. 2002). Smokers require a longer healing time after fractures and will have a higher incidence of non-union of broken bones, infection and/or flap necrosis.

In the present study an overall mean bone loss of $0.34 \mathrm{~mm}$ was found with implant insertion as baseline value. Recent studies evaluating peri-implant bone level changes around implants with a fluoride-modified surface, reported mean bone level changes of $0.25-0.50$ mm (Donati et al. 2008; Stanford et al. 2008; Toljanic et al. 2008). In a recent systematic review a mean value of $0.25 \mathrm{~mm}$ was found (Laurell \& Lundgren. 2009) for grit-blasted implants without fluoride modification. The included studies reported on bone level changes from the time of prosthetic loading or second stage surgery, were the initial bone remodeling prior to prosthetic loading is not taken into account. As described by Åstrand and co-workers (2004) major changes in peri-implant bone level can take place between implant insertion and prosthetic loading. Additionally, Cooper and co-workers (2001) concluded that bone loss around early loaded implants amounted to $0.40 \mathrm{~mm}$ during the first six weeks of loading, while no further bone loss could be observed following the subsequent year. One could conclude that if the radiographic analysis is performed many months after implant insertion the total bone loss may be underestimated. Hence in the present study, a mean bone loss of $0.34 \mathrm{~mm}$ from time of implant insertion can be considered very successful.

As smoking is a systemic factor, peri-implant bone loss was analyzed on patient level. Moreover, calculation of peri-implant bone loss was also performed with the individual implant as statistical unit because a calculation on patient level may hide clinical complications when multiple implants are placed (De Bruyn \& Collaert 2008; Misch et al. 2008). In the present study bone loss was $0.33 \mathrm{~mm}$ when calculated with the patient as statistical unit but the range decreased massively $(0.00-7.10 \mathrm{~mm}$ vs $0.00-4.90 \mathrm{~mm})$. 
Indeed, one implant with extended bone loss can be masked when other implants in the same patient present no bone loss at all. Hence calculating individual peri-implant bone loss is an appropriate way to evaluate biological complications.

Findings from the present study show that the mean peri-implant bone loss is higher in smokers compared with nonsmokers. This is in accordance with other studies summarized in Table 1 whereby 15 out of 16 studies reported a significant difference. In 7 studies out of 16 , separate values were not reported for smokers and nonsmokers but it was mentioned that a significant difference was observed. The difference in the present study was observed in the maxilla, but could not be found in the mandible. These results are in accordance with previous studies (Haas et al. 1996; Vandeweghe et al. 2009). This leads to the question what different effect cigarette smoking can have on the maxilla and the mandible. A possible explanation is that the mandible is partially protected by the tongue, preventing direct influences from tobacco smoke to the peri-implant tissues (Haas et al. 1996; Vandeweghe et al. 2009). This might explain the better results in the mandible, comparable to the results in nonsmokers. Moreover it is reasonable to believe, as bone quality is in generally more favorable in the mandible (Trulhar et al. 1997), that the maxilla is more subject to the pernicious effect of smoking over the years.

In the present paper an overall success rate of $95 \%$ is found. Only $5 \%$ of the implants lost > $1.5 \mathrm{~mm}$ during the first year of loading and additionally $>0.2 \mathrm{~mm}$ per year (Albrektsson et al. 1986). One should keep in mind that these criteria does not deal with bone remodeling before prosthetic loading, probably giving an underestimation of the success rate in this study. If we lower the threshold for success to $<1 \mathrm{~mm}$ of bone loss as proposed by De Bruyn \& Collaert (2008), an overall success rate of $90.6 \%$ is found. Recently, implant success was defined as $<2.0 \mathrm{~mm}$ of bone loss from the time of implant insertion (Misch et al. 2008). A success rate of $95.7 \%$ was found according to the latter. Taken into account that different baseline values and different success criteria are used in literature, making a comparison between studies on implant success is extremely difficult.

Finally, surface modifications (Degidi et al. 2006; Fischer et al. 2008; Donati et al. 2008; Stanford et al. 2008; Toljanic et al. 2008) can influence bone preservation. Despite this enhanced outcome, smokers are more likely to experience implant failure and maxillary peri- 
implant bone loss. A recent comparative, controlled, prospective study by Shibli and coworkers (2010) comparing bone healing in smokers and nonsmokers around implants with an anodized surface showed more marginal bone loss and fibrous tissue in smokers. Also bone-to-implant contact and bone density in the threaded area were significantly lower compared to nonsmokers. Randomized controlled trials are warranted to investigate the effect of surface modifications on long-term bone preservation in smokers.

\section{CONCLUSION}

The present study is the first to compare peri-implant bone loss in smokers and nonsmokers from the time of implant insertion (baseline) to at least 2 years of follow-up. Implants with a fluoride-modified surface demonstrated a high survival rate and limited bone loss. However, smokers are more prone to experience implant failure and show more peri-implant bone loss in the maxilla. Whether this bone loss is predicting future biological complications remains to be evaluated. Prospective studies are required to assess the dose-dependent effect of smoking on implant outcomes. In the mean time all patients should be informed about smoking cessation.

\section{ACKNOWLEDGEMENT}

The retrospective analysis of the data was supported by a grant of Astra Tech, Mölndahl, Sweden.

\section{REFERENCES}

Aalam, A.A. \& Nowzari, H. (2005) Clinical Evaluation of dental implants with surfaces roughened by anodic oxidation, dual acid etched implants and machined implants. International Journal of Oral and Maxillofacial Implants 20: 793-798.

Albrektsson ,T., Zarb, G., Worthington, P. \& Eriksson, A.R. (1986) The long-term efficacy of currently used dental implants: a review and proposed criteria of success. International Journal of oral and Maxillofacial Implants 1: 11-25.

Al-Nawas, B., Krämmerer, P.W., Morbach, T., Ladwein, C., Wegerer, J., \& Wagner, W. (2010) Ten-year retrospective follow-up study on the TiOblast dental implant. Clinical Implant Dentistry and Related Research 11 (Epub ahead of print).

Anner, R., Grossmann, Y., Anner, Y. \& Levin, L. (2010) Smoking, diabetes mellitus periodontitis and supportive periodontal treatment as factors associated with dental implant 
survival: a long-term retrospective evaluation of patients followed for up to 10 years. Implant Dentistry 19: 57-64.

Attebring, M., Herlitz, J., Berndt, A.K., Karlsson, T. \& Hjalmarson, A. (2001) Are patients truthful about their smoking habits? A validation of self-report about smoking cessation with biochemical markers of smoking activity amongst patients with ischaemic heart disease. Journal of Internal Medecine 249: 145-151.

Bain, C.A. \& Moy, P.K. (1993) The association between failure of dental implants and cigarette smoking. International Journal of Oral and Maxillofacial Implants 8: 609-615.

Baljoon, M., Natto, S. \& Bergstrom, J. (2004) The association of smoking with vertical periodontal bone loss. Journal of Periodontology 75: 844-851.

Berglundh, T., Abrahamsson, I., Albouy, J.P. \& Lindhe, J. (2007) Bone healing at implants with a fluoride-modified surface: an experimental study in dogs. Clinical Oral Implants Research 18: $147-52$.

Bergström, J., Persson, L. \& Preber, H. (1988) Influence of cigarette smoking on vascular reaction during experimental gingivitis. Scandinavian Journal of Dental research 96: 34-39.

Carlsson, G.E., Lindquist, L.W. \& Jemt, T. (2000) Long-term marginal periimplant bone loss in edentulous patients. International Journal of Prosthodontics 13, 295-302.

Collaert, B. \& De Bruyn, H. (2008) Immediate functional loading of TiOblast dental implants in full-arch edentulous maxillae: a 3-year prospective study. Clinical Oral Implants Research 19: 1254-1260.

Cooper, L., Felton, D.A., Kugelberg, C.F., Ellner, S., Chaffee, N., Molina, A.L., Moriarty, J.D., Paquette, D. \& Palmqvist, U. (2001) A multicenter 12-month evaluation of single-tooth implants restored 3 weeks after 1-stage surgery. International Journal Oral \& Maxillofacial Implants 16: 182-192.

Cooper, .LF., Zhou, Y., Takebe, J., Guo, J., Abron, A., Holmen, A. \& Ellingsen, J.E. (2006) Fluoride modification effects on osteoblast behavior and bone formation at $\mathrm{TiO} 2$ grit-blasted c.p. titanium endosseous implants. Biomaterials 27: 926-36.

Cooper, L., Moriarty, J.D., Guckes, A.D., Klee, L.B., Smith, R.G., Almgren, C.\& Felton D.A. (2008) Five-year prospective evaluation of mandibular overdentures retained by two microthreated, TiOblast nonsplinted implants and retentive ball anchors. International Journal of Oral and Maxillofacial Implants 23: 696-704.

D’ Avila, S., dos Reis, L.D., Piattelli, A., Aguiar, K.C., De Faveri, M., Borges, F.L., lezzi, G., Oliveira, N.T., de G Cardoso, L.A., \& Shibli, J.A . (2010) Impact of smoking on human bone apposition at different dental implant surfaces: a histologic study in type IV bone. Journal of Oral Implantology 36: 85-90. 
De Bruyn, H. \& Collaert, B. (1994) The effect of smoking on early implant failure. Clinical Oral Implants Research 5: 260-264.

De Bruyn, H., Van de Velde, T. \& Collaert, B. (2008) Immediate functional loading of TiOblast dental implants in full-arch edentulous mandibles: a 3-year prospective study. Clinical Oral Implants Research 19: 717-723.

De Bruyn, H. \& Collaert, B. (2008) Effect of Microthread design on preservation of marginal bone loss. Applied Osseointegration Research 7: 38-47.

Degidi, M., Perrotti, V., Piattelli, A. (2006) Immediately loaded titanium implants with a porous anodized surface with at least 36 months of follow-up. Clinical Implant Dentistry and Related Research 8: 169-177.

DeLuca, S. \& Zarb, G. (2006) The effect of smoking on osseointegrated dental implants.Part II: Peri-implant bone loss. International Journal of Prosthodontics 19: 560-566.

Donati, M., La Scala, V., Billi, M., Di Dino, B., Torrisi, P. \& Berglundh, T. (2008) Immediate functional loading of implants in single tooth replacement: a prospective clinical multicenter study. Clinical Oral Implants Research 19: 740-748.

Ellingsen, J.E., Johansson, C.B., Wennerberg, A. \& Holmén, A.(2004) Improved retention and bone-to-implant contact with fluoride-modified titanium implants. International Journal of Oral and Maxillofacial Implants 19: 659-66.

Esposito, M., Hirsch, J.M., Lekholm, U. \& Thomsen, P.(1998) Biological factors contributing to failures of osseointegrated oral implants. (II). Etiopathogenesis. European Journal of Oral Sciences 106: 721-764.

Feloutzis, A., Lang, N.P., Tonetti, M.S., Burgin, W., Bragger, U., Buser, D., Duff, G.W. \& Kornman, K.S. (2003) IL-1 gene polymorphism and smoking as risk factors for peri-implant bone loss in a well-maintained population. Clinical Oral Implants Research 14: 10-17.

Fielding, J.E. (1985) Smoking: health effects and control (1). New England Journal of Medecine 313: 491-498

Fischer, K., Stenberg, T., Hedin, M. \& Sennerby, L. (2008) Five-year results from a randomized, controlled trial on early and delayed loading of implants supporting full-arch prosthesis in the edentulous maxilla. Clinical Oral Implants Research 19: 433-441.

Galindo-Moreno, P., Fauri, M., Ávila-Ortiz, G., Fernández-Barbero, .J.E, Cabrera-León, A. \& Sánchez-Fernández, E. (2005) Influence of alcohol and tobacco habits on peri-implant marginal bone loss: a prospective study. Clinical Oral Implants Research 16: 579-586.

Gorman, L.M., Lambert, P.M., Morris, H.F., Ochi, S. \& Winckler,S. (1994) The effect of smoking on implant survival at second stage surgery: DICRG intern report no. 5. Dental Implant Clinical Research Group. Implant Dentistry 3: 165-168. 
Guo, J., Padilla, R.J., Ambrose, W., De Kok I.J. \& Cooper, L. (2007) The effect of hydrofluoric acid treatment of $\mathrm{TiO}(2)$ grit blasted titanium implants on adherent osteoblast gene expression in vitro and in vivo. Biomaterials 28: 5418-5425.

Haas, R., Haimbock, W., Mailath, G. \& Watzek, G. (1996) The relationship of smoking on periimplant tissue: a retrospective study. Journal of Prosthetic Dentistry 76: 592-596.

Hinode, D., Tanabe, S., Yokoyama, M., Fujisawa, K., Yamauchi, E. \& Miyamoto, Y. (2006) Influence of smoking on osseointegrated implant failure: a meta-analysis. Clinical Oral Implants Research 17: 473-478.

Hoogendoorn, J.M., Simmermacher, R.K., Schellekens, S.S. \& Van der Werken, C. (2002) [Adverse effects of smoking on healing of bones and soft tissues]. Unfallchirurg 105: 76-81.

Isa, Z.M., Schneider G.B., Zaharias, R., Seabold, D. \& Stanford C.M. (2006) Effects of fluoridemodified titanium surfaces on osteoblast proliferation and gene expression. International Journal of Oral and Maxillofacial Implants 21: 203-211.

Johnson, N.W. \& Bain, C.A. (2000) Tobacco and Oral disease. Britisch Dental Journal 189 : 2000-2006.

Jorgensen, L.N., Kallehave, F., Christensen, E., Siana, J.E. \& Gottrup, F. (1998) Less collagen production in smokers. Surgery 123: 450-455.

Kandell, D.B., Schaffran, C., Griesler, P.C., Hu, M.C., Davies, M. \& Benowitz, M. (2006) Salivary cotinine concentration vs self-reported cigarette smoking: Three patterns of inconsistency in adolescence. Nicotine and Tobacco Research 8: 525-537.

Karoussis, I.K., Müller, S., Salvi, G.E., Heitz-Mayfield, L.J., Brägger, U. \& Lang, N.P.(2004) Association between periodontal and peri-implant conditions: a 10-year prospective study. Clinical Oral Implants Research 15: 1-7.

Kenney, E.B., Kraal, J.H., Saxe, S.R. \& Jones, J. (1977) The effect of cigarette smoking on human PMN leukocytes. Journal of Periodontal Research 12: 227-23.

Koldsland, O.C., Scheie, A.A. \& Aass, A.M. (2009) Prevalence of implant loss and the influence of associated factors. Journal of Periodontology 80: 1069-1075.

Kornman, K.S. \& Robertson, P.B. (2000) Fundamental principels affecting the outcomes of therapy for osseous lesions. Periodontology 2000 22: 22-43.

Lambert, P.M., Morris, H.F. \& Ochi, S. (2000) The influence of smoking on 3-year clinical success of osseointegrated dental implants. Annals of Periodontology 5: 79-89.

Laurell, L. \& Lundgren, D. Marginal bone level changes at dental implants after 5 years in function: a meta-analysis. Clinical Implant Dentistry and Relates Research 3 (Epub ahead of print). 
La Vecchia, C., Boyle, P., Franceschci, S., Levi, F., Maisonneuve, P., Negri, E., Lucchini, F. \& Smans, M. (1991) Smoking and cancer with emphasis on Europe. European Journal of Cancer 27: 94-104.

Lehr, H.A. (2000) Micorcirculatory dysfunction induced by cigarette smoking. Micorcirulation 7: 367-384.

Levin, L., Hertzberg, R., Har-Nes, S. \& Schwartz-Arad, D. (2008) Long-term marginal bone loss around single dental implants affected by current and past smoking habits. Implant Dentistry 17: 422-429.

Lindquist, L.W., Carlsson, G.E. \& Jemt, T. (1996) A prospective 15-year follow-up study of mandibular fixed prostheses supported by osseointegrated implants. Clinical results and marginal bone loss. Clinical Oral Implants Research 7: 329-336.

Lindquist, L.W., Carlsson, G.E. \& Jemt, T. (1997) Association between marginal bone loss around osseointegrated mandibular implants and smoking habits: a 10-year follow-up study. Journal of Dentl Research 76: 1667-1674.

MacFarlane, G.D., Hetzberg, M.C., Wolff, L. \& Hardie, N.A. (1992) Refractory periodontitis associated with abnormal PMN leukocyte phagocytosis and cigarette smoking. Journal of Periodontology 63: 908-913.

Masaki, C., Schneider G.B., Zaharias, R., Seabold, D. \& Stanford, C. (2005) Effects of implant surface topography on esteoblast gene expression. Clinical Oral Implants Research 16: 650656.

Meechan, J.G., MacGregor, G.M., Rogers, S.M., Hobson, R.S., Bate, J.P. \& Dennison, M. (1988) The effects of smoking on post-extraction socket filling with blood and on the incidence of painful sockets. Brtisch Journal of Oral and Maxillofacial Surgery 26: 402-409.

Millar, W.J. \& Locker, D. (2007) Smoking and oral health status. Journal of Canadian Dental Association 73: 155.

Misch, C.E., Perel, M.L., Wang, H.L., Sammartine, G., Galindo-Moreno, P., Trisi, P., Steigmann, M., Rebaudi, A., Palti, A., Pikos, M.A., Schwartz-Arad, D., Choukroun, J., Guttierez-Perez, J.L., Marenzi, G. \& Valavanis, D.K. (2008) Implant success, survival and failure: the International Congress of Oral Implantologists (ICOI) Pisa Consensus Conference. Implant dentistry 17: 515.

Moy, P.K., Medina, D., Shetty, V. \& Aghaloo, T.L. (2005) Dental implant failure rates and associated risk factors. International Journal of Oral and Maxillofacial Implants 20: 569-577.

Nitzan, D., Mamlider, A., Levin, L. \& Schwartz-Arad, D. (2005) Impact of smoking on marginal bone loss. International Journal of Oral and Maxillofacial Implants 20: 605-609.

Palmer, R.M., Wilson, R.F., Hasan, A.S. \& Scott, D.A. (2005) Mechanisms of action of environmental factors - tobacco smoking. Journal of Clinical Periodontology 32: 180-195. 
Penarrocha, M., Palomar, M., Sanchis, J.M., Guarinos, J. \& Balaguer, J. (2004) Radiologic study of marginal bone loss around 108 dental implants and its relationship to smoking, implant location, and morphology. International Journal of Oral and Maxillofacial Implants 19: 861-867.

Peto, R., Lopez, A.D., Boreham, J., Thun, M., Heath, C. Jr. \& Doll, L. (1996) Mortality from smoking worldwide. British Medical Bulletin 52: 12-21.

Preber, H. \& Bergström, J. (1985) Occurrence of gingival bleeding in smoker and non-smoker patients. Acta Odontologica Scandinavia 43: 355-320.

Roediger, M., Huels, A.,Schliephake, H., McGlumphy, G. \& Philips, K. (2009) Early loading of fluoride modified implants in the posterior mandible. Journal of Dental Research 84: 3385.

Scabbia, A., Cho, K.S., Sigurdsson, T.J., Kim, C.K. \& Trombelli, L. (2001) Cigarette smoking negatively affects healing response following flap debridement surgery. Journal of Periodontology 72: 43-49.

Schwarz-Arad, D., Samet, N. \& Mamlider, A. (2002) Smoking and complications of endosseus dental implants. Journal of Periodontology 73: 153-157.

Schwartz-Arad, D., Kidron, N. \& Dolev, E. (2005) A long-term study of implants supporting overdentures as a model for implant success. Journal of Periodontology 76: 1431-1435.

Shibli, J.A., Piattelli, A., lezzi, G., Cardoso, L.A., Onuma, T., de Carvalho, P.S., Susana, Ferrari, D.S., Mangano, C. \& Zenobio, E.G. (2010) Effect of smoking on early bone healing around oxidized surfaces: a prospective controlled study in human jaws. Journal of Periodontology 81: 575-583.

Stanford, C., Schneider, G.B., Masaki, C., Zaharias, R., Seabold, D., Eckdahl, J., et al. (2006) Effects of fluoride-modified titanium dioxide grit blasted implant surfaces on platelet activation and osteoblast differentiation. Applied Osseointegration Research 5: 24-30.

Stanford, C., Johnson, G., Fakhry, A., Aquilino, S., Gratton, D., Reinke, M. \& Asmussen, C. (2008) Three year post-moading outcomes with Microthread OsseoSpeed dental implants placed in the posterior maxilla. Applied Osseointegration Research 7: 49-57.

Steveling, H., Mertens, C. \& Merkle, K. (2009) Bioactive implants: 5 years of experience with a fluoridized surface. Journal of Clinical Periodontology 36: 197.

Strietzel, F.P., Reichart, P.A., Kale, A., Kulkarni, M., Wegner, B. \& Küchler, I. (2007) Smoking interferes with the prognosis of dental implant treatment: a systematic review and metaanalysis. Journal of Clinical Periodontology 34: 523-544.

Thor, A., Rasmusson, L., Wennerberg, A., Thomsen, P., Hirsch, J.M., Nilsson, B. \& Hong, J. (2007) The role of whole blood in thrombin generation in contact with various titanium surfaces. Biomaterials 28: 966-974. 
Toljanic, J., Baer, R., Ekstrand, K. \& Thor, A. (2009) Implant rehabilitation of the aftrophic edentulous maxilla including fixed provisional restoration without the use of bone grafting: a review of 1-year outcome data from a long-term prospective clinical trial. International Journal of Oral and Maxillofacial Implants 24: 518-526.

Tolstunov, L. (2007) Implant zones of the jaw: implant location and related success rate. Journal of Oral Implantology 4: 211-220.

Trulhar, R.S., Orenstein, I.H., Morris, H.F. \& Ochi, S. (1997) Distribution of bone quality in patients recieving endosseous dental implants. Journal of Oral and Maxillofacial Surgery $\mathbf{5 5}$ 38-45.

Van de Velde, T., Collaert, B., Sennerby, L. \& De Bruyn, H. (2010) Effect of implant design on preservation of marginal bone in the mandible. Clinical Implant Dentistry and Related research 12: 134-141.

Vandeweghe, S. \& De Bruyn, H. (2009) The effect of smoking on early bone remodeling around surface modified Southern implants. Clinical Implant Dentistry and Related Research [Epub ahead of print].

Warnakulasuriya, S., Dietrich, T., Bornstein, M., Peidro, E.C., Preshaw, P.M., Walter, C., Wennström, J.L. \& Bergström, J. (2010) Oral health risks of tobacco use and effects of cessation. International Dental Journal 60: 7-30.

Wennström, .L.J, Zurdo, J., Karlsson, S., Ekestubbe, A., Gröndahl, K. \& Lindhe, J. (2004a)Bone level change at implant-supported fixed partial dentures with and without cantilever extension after 5 years in function. Journal of Clinical Periodontology 31: 1077-1083.

Wennström, J.L., Ekestubbe, A., Gröndahl, K., Karlsson, S. \& Lindhe, J. (2004b) Oral rehabilitation with implant-supported fixed partial dentures in periodontitis-susceptible subjects. A 5-year prospective study. Journal of Clinical Periodontology 31: 713-724.

Zarb, G.A. \& Albrektsson, T. (1998) Consensus report: Towards optimized treatment outcomes for dental implants. International Journal of Prosthodontics 11: 389. 


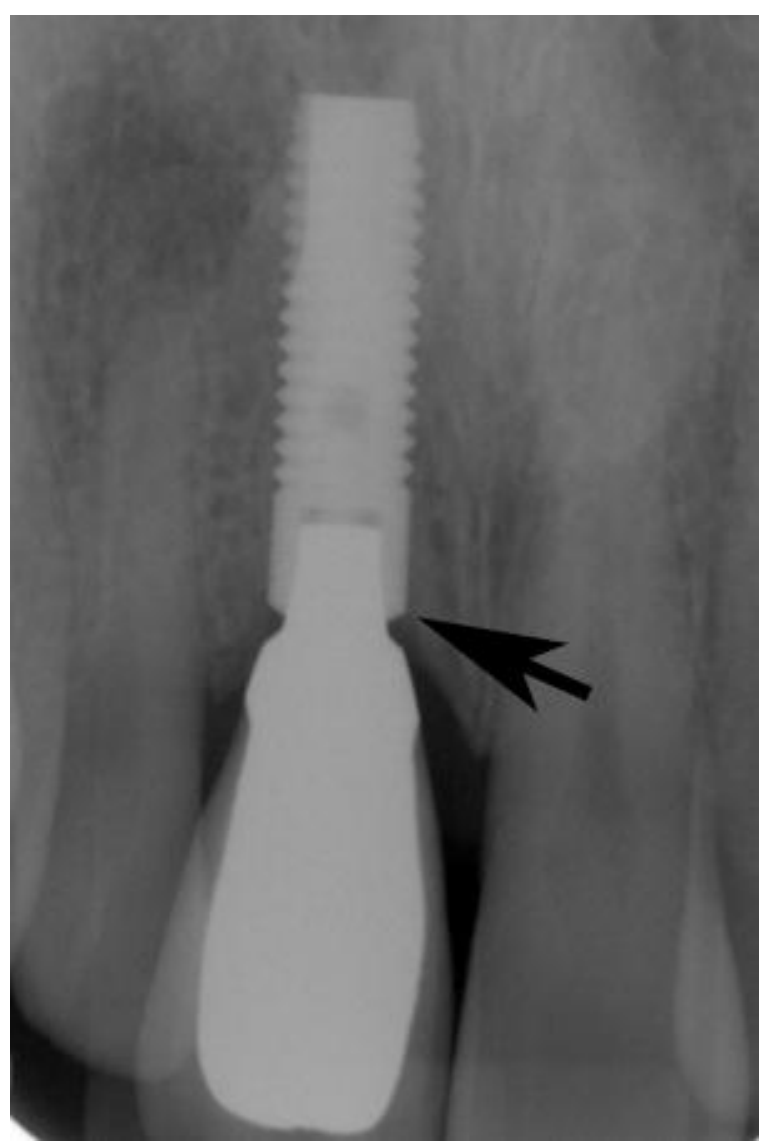

Figure 1. Reference point (lower border of the smooth implant collar or the uppermost point of the microthreaded part) indicated by black arrow. 


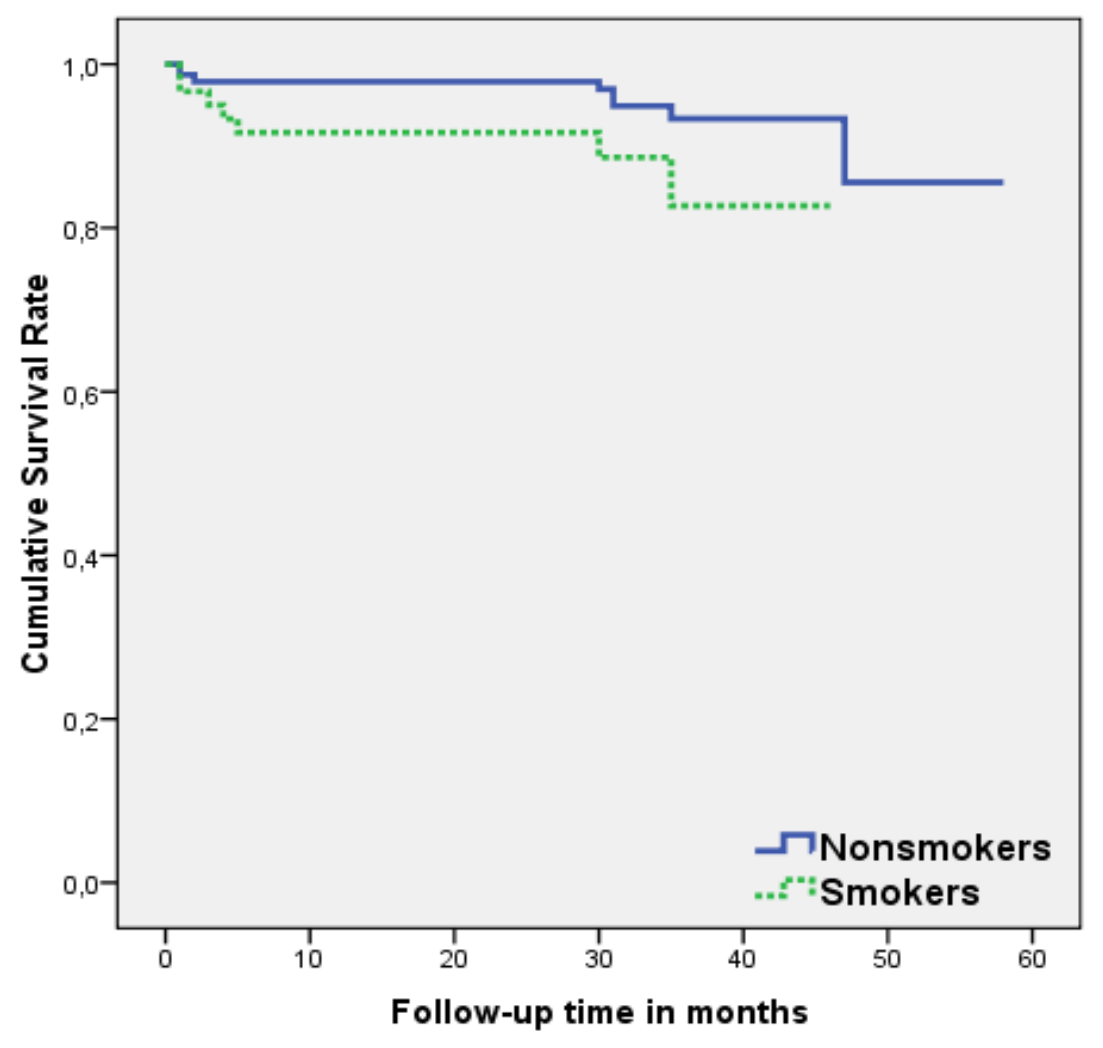

Figure 2. Kaplan-Meier Survival Curve showing estimated implant failures in function of time for smokers and nonsmokers with the patient as statistical unit. 


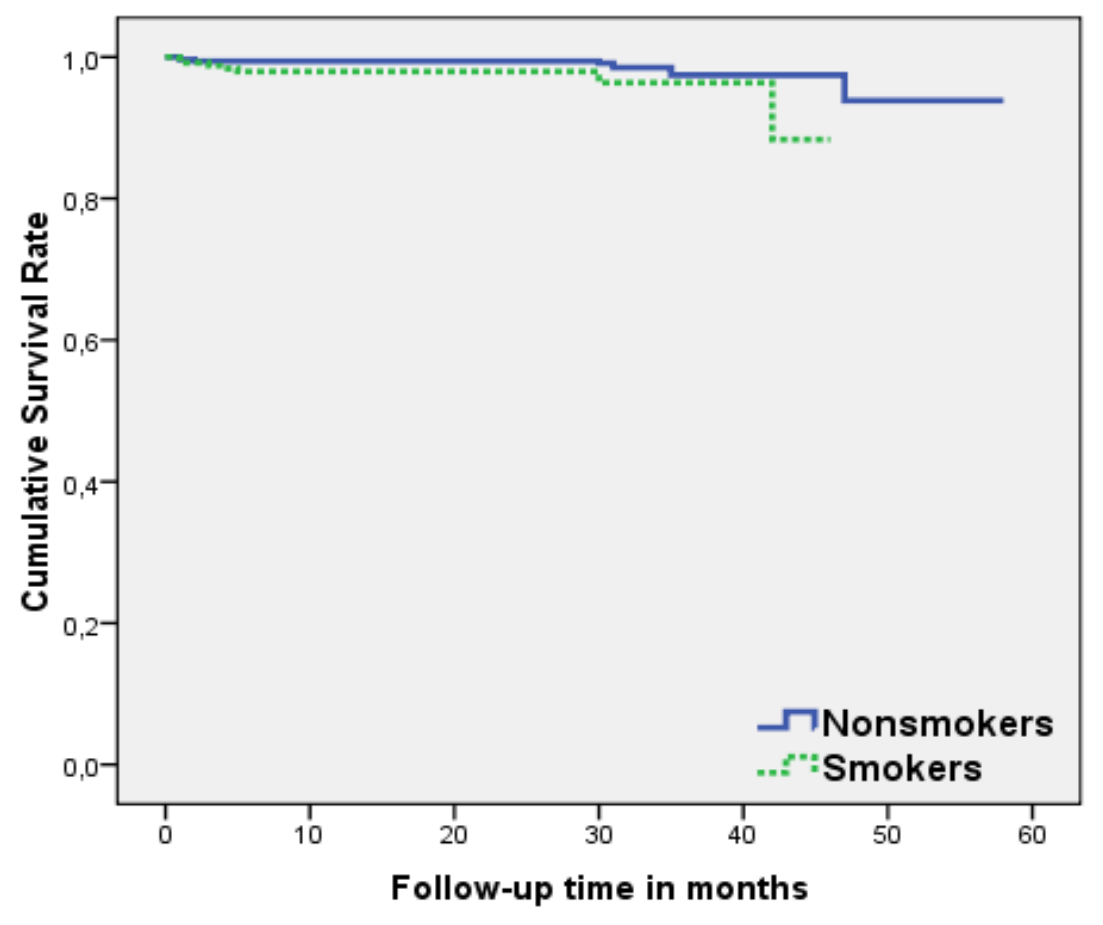

Figure 3. Kaplan-Meier Survival Curve showing estimated implant failures in function of time for smokers and nonsmokers with the implant as statistical unit. 


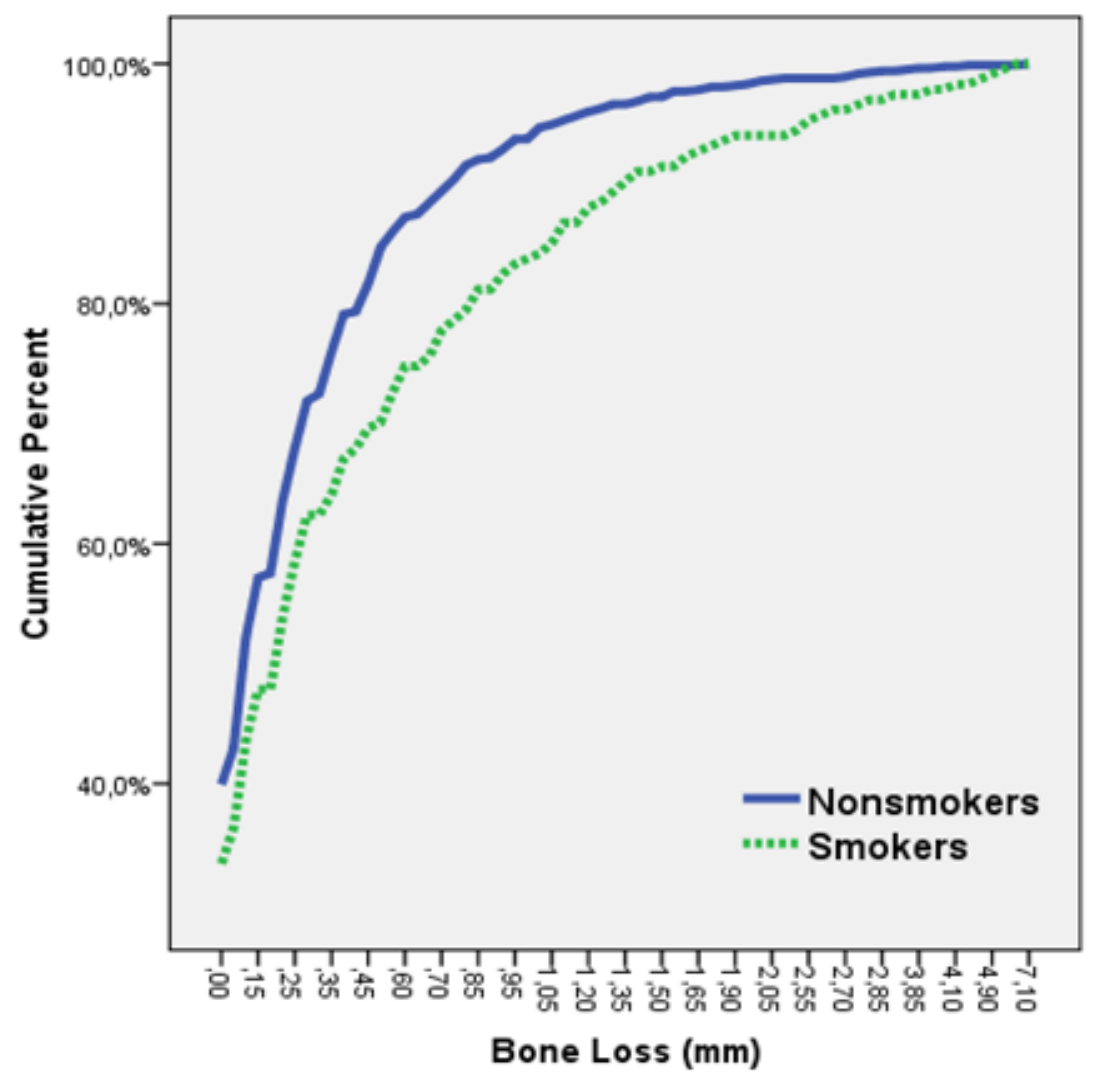

Figure 4. Cumulative percentage of individual peri-implant bone loss based on available radiographs $(n=1076)$, smokers $(n=234)$ compared to nonsmokers $(n=829)$. 


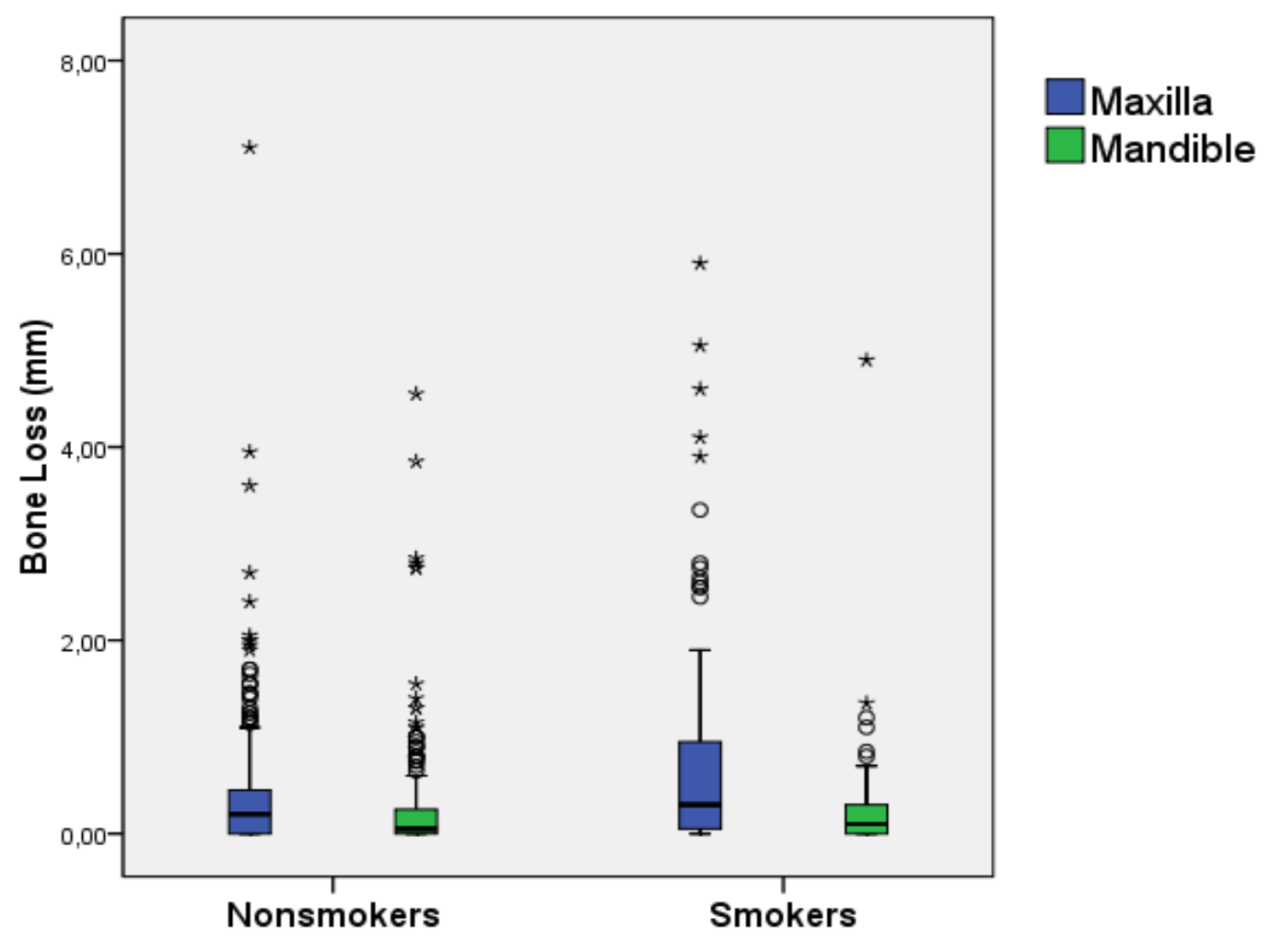

Figure 5. Boxplot presenting individual peri-implant bone loss in smokers and nonsmokers after at least 2 years, comparing maxilla ( $n=492$ in nonsmokers; $n=137$ in smokers) and mandible $(n=337$ in nonsmokers; $n=97$ in smokers). 


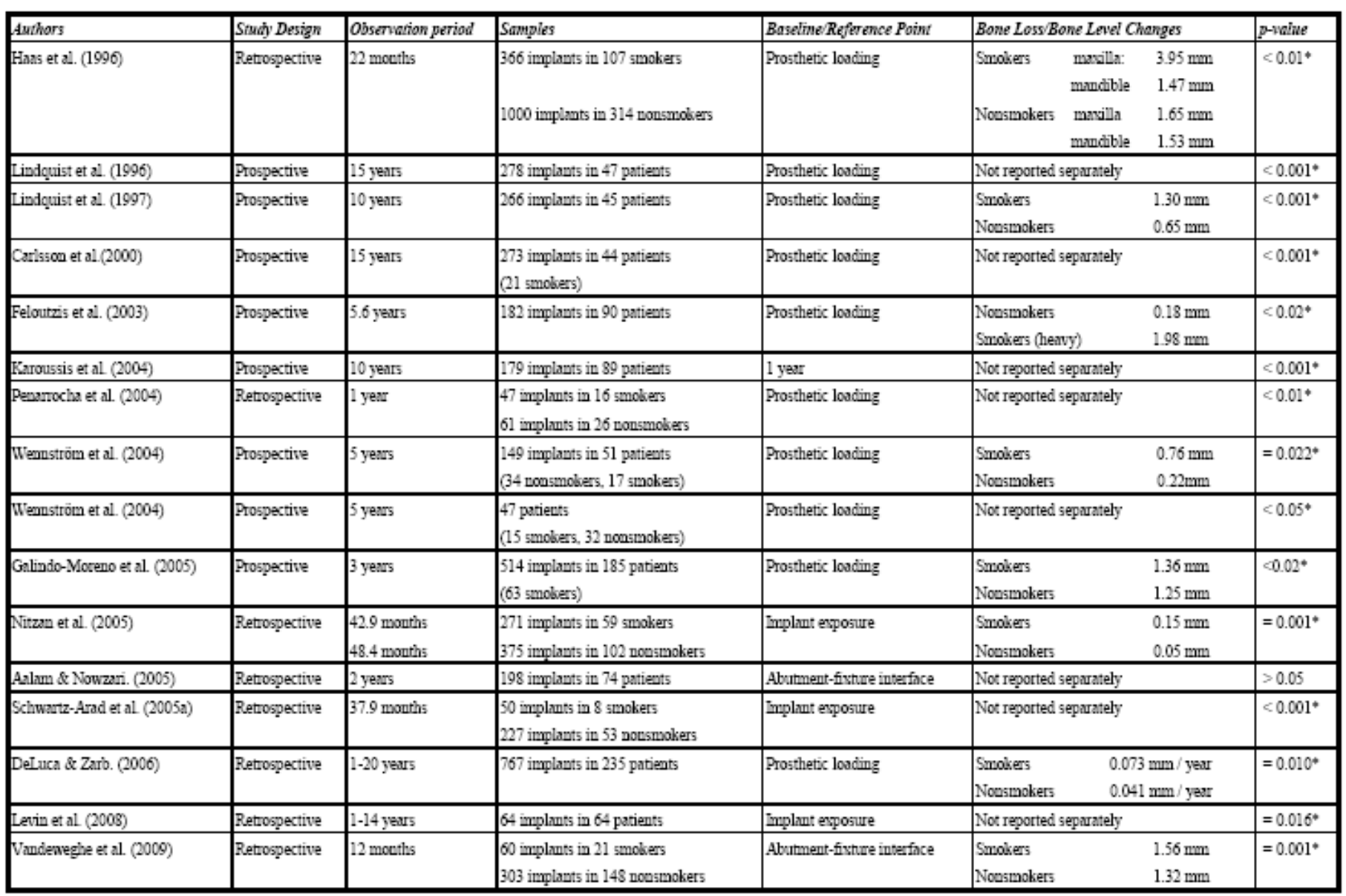

Table 1. Overview of studies comparing peri-implant bone loss is smokers and nonsmokers. * Statistically significant difference was found between smokers and nonsmokers.

\begin{tabular}{|c|c|c|c|c|}
\hline \multicolumn{2}{|c|}{ Implant Survival group } & & \multicolumn{2}{|c|}{ Implant bone loss group } \\
\hline Implants & Patients & & Implants & Patients \\
\hline $1106(19)$ & $300(17)$ & Total & 1076 & 295 \\
\hline $244 \quad(8)$ & $60 \quad(7)$ & Smokers & 234 & 60 \\
\hline $849 \quad(11)$ & $235(10)$ & Nonsmokers & 829 & 230 \\
\hline 13 & 5 & Unknown smoking status & 13 & 5 \\
\hline $648 \quad(5)$ & $170(5)$ & Maxilla & 636 & 168 \\
\hline $458 \quad(14)$ & $156(12)$ & Mandible & 440 & 151 \\
\hline
\end{tabular}

Table 2.Implant and patient distribution with respect to smoking status and jaw. Failures are given between brackets. 


\begin{tabular}{|c|l|l|l|l|l|l|l|}
\hline & \multicolumn{7}{|c|}{ Length (mm) } \\
\hline & & $\mathbf{8 . 0 0}$ & $\mathbf{9 . 0 0}$ & $\mathbf{1 1 . 0 0}$ & $\mathbf{1 3 . 0 0}$ & $\mathbf{1 5 . 0 0}$ & $\mathbf{1 7 . 0 0}$ \\
\cline { 2 - 9 } Diameter & $\mathbf{3 . 5 0}$ & $37(3)$ & $24(2)$ & 26 & $110(2)$ & 87 & 0 \\
\hline $\mathbf{( m m )}$ & $\mathbf{4 . 0 0}$ & $36(2)$ & $33(1)$ & $39(1)$ & $133(1)$ & $192(1)$ & $8(1)$ \\
\cline { 2 - 9 } & $\mathbf{4 . 5 0}$ & 0 & $30(1)$ & 12 & 67 & 48 & 0 \\
\hline & $\mathbf{5 . 0 0}$ & 0 & 32 & $17(2)$ & $28(1)$ & 40 & 0 \\
\hline
\end{tabular}

Table 3. Im plant distribution according to implant length and diameter. Failed implants are given between brackets.

\begin{tabular}{|c|c|c|c|c|c|c|c|c|c|c|c|c|}
\hline & & & & & & PATIENT & & & & & \\
\hline & Smokers & & \multicolumn{2}{|c|}{ Nonsmokers } & Overall & & Smokers & & \multicolumn{2}{|c|}{ Nonsmokers } & Overall & \multirow[b]{2}{*}{ CSR } \\
\hline & \begin{tabular}{|l|} 
Failures \\
\end{tabular} & CSR & Failures & CSR & Failures & CSR & Failures & CSR & Failures & CSR & Failures & \\
\hline $0-5 \mathrm{~m}$ & $5(244)$ & $98,00 \%$ & $5(849)$ & $99,40 \%$ & $10(1106)$ & $99,10 \%$ & $5(60)$ & \begin{tabular}{|l|}
$91,70 \%$ \\
\end{tabular} & $5(235)$ & $97,90 \%$ & $10(300)$ & $96,70 \%$ \\
\hline $6-11 m$ & $0(239)$ & $98,00 \%$ & $0(844)$ & $99,40 \%$ & $0(1096)$ & $99,10 \%$ & $0(55)$ & $91,70 \%$ & $0(230)$ & $97,90 \%$ & $0(290)$ & $96,70 \%$ \\
\hline $12-17 \mathrm{~m}$ & $0(239)$ & $98,00 \%$ & $0(844)$ & $99,40 \%$ & $0(1096)$ & $99,10 \%$ & $0(55)$ & $91,70 \%$ & $0(230)$ & $97,90 \%$ & $0(290)$ & $96,70 \%$ \\
\hline $18-23 \mathrm{~m}$ & $0(239)$ & $98,00 \%$ & $0(844)$ & $99,40 \%$ & $0(1096)$ & $99,10 \%$ & $0(55)$ & $91,70 \%$ & $0(230)$ & $97,90 \%$ & $0(290)$ & $96,70 \%$ \\
\hline $24-29 m$ & $0(239)$ & $98,00 \%$ & $0(844)$ & $99,40 \%$ & $0(1096)$ & $99,10 \%$ & $0(55)$ & $91,70 \%$ & $0(230)$ & $97,90 \%$ & $0(290)$ & $96,70 \%$ \\
\hline $30-35 \mathrm{~m}$ & $2(124)$ & $96,40 \%$ & $5(364)$ & $97,40 \%$ & $7(499)$ & $95,80 \%$ & $1(30)$ & $88,60 \%$ & $4(108)$ & $93,30 \%$ & $5(142)$ & $91,30 \%$ \\
\hline $36-41 \mathrm{~m}$ & $0(48)$ & $96,40 \%$ & $0(148)$ & $97,40 \%$ & $0(202)$ & $95,80 \%$ & $0(13)$ & $88,60 \%$ & $0(53)$ & $93,30 \%$ & $0(68)$ & $91,30 \%$ \\
\hline $42-47 m$ & $1(12)$ & $88,30 \%$ & $1(51)$ & $93,80 \%$ & $2(67)$ & $92,20 \%$ & $1(4)$ & $82,70 \%$ & $1(21)$ & $85,60 \%$ & $2(26)$ & $83,70 \%$ \\
\hline $48-53 m$ & $0(0)$ & $88,30 \%$ & $0(19)$ & $93,80 \%$ & $0(19)$ & $92,20 \%$ & $0(0)$ & $82,70 \%$ & $0(9)$ & $85,60 \%$ & $0(9)$ & $83,70 \%$ \\
\hline \multirow[t]{2}{*}{$54-58 \mathrm{~m}$} & $0(0)$ & $88,30 \%$ & $0(2)$ & $93,80 \%$ & $0(2)$ & $92,20 \%$ & $0(0)$ & $82,70 \%$ & $0(2)$ & $85,60 \%$ & $0(2)$ & $83,70 \%$ \\
\hline & \multicolumn{4}{|c|}{ smokers vs nonsmokers: $p=0.025$} & & & \multicolumn{4}{|c|}{ smokers vs nonsmokers: $p=0.017$} & & \\
\hline
\end{tabular}

Table 4. Overview of failures and cumulative survival rates in smokers and nonsmokers.

The total number of patients/implants at the start of the follow-up period is given between brackets.

\begin{tabular}{|l|l|l|l|l|l|l|l|l|l|l|l|l|l|l|l|l|}
\hline & \multicolumn{9}{|c|}{ IMPLANT } & \multicolumn{9}{|l|}{ PATIENT } \\
\hline
\end{tabular}

Table 5. Overview of failures and cumulative survival rates in smokers and nonsmokers with respect to the jaw.

The total number of patients/implants at the start of the follow-up period is given between brackets.

\begin{tabular}{|c|c|c|c|}
\hline IMPLANT & nonsmoker & smoker & $p$ value \\
\hline Maxilla + Mandible & $0,29 \mathrm{~mm} \mathrm{n}=829(\mathrm{SD} 0.54)$ range: $0.00-7.10$ & $0,53 \mathrm{~mm} \mathrm{n}=234(\mathrm{SD} 0.92)$ range: $0.00-5.90$ & $\mathrm{p}<0.001^{*}$ \\
\hline Maxilla & $0,33 \mathrm{~mm} \mathrm{n}=492(\mathrm{SD} 0.65)$ range: $0.00-7.10$ & $0,74 \mathrm{~mm} \mathrm{n}=137(\mathrm{SD} 1.07)$ range: $0.00-5.90$ & $\mathrm{p}<0.001^{*}$ \\
\hline Mandible & $0,22 \mathrm{~mm} n=337(\mathrm{SD} 0.50)$ range: $0.00-4.55$ & $0,25 \mathrm{~mm} \mathrm{n}=97 \quad(\mathrm{SD} 0.56)$ range: $0.00-4.90$ & $p=0.298$ \\
\hline p value & $\mathrm{p}<0.001^{*}$ & $\mathrm{p}<0.001^{*}$ & \\
\hline \multicolumn{4}{|l|}{ PATIENT } \\
\hline Maxilla + Mandible & $0,30 \mathrm{~mm} \mathrm{n}=235(\mathrm{SD} 0.65)$ range: $0.00-4.90$ & $0.46 \mathrm{~mm} \mathrm{n}=65(\mathrm{SD} 0.56)$ range: $0.00-2.80$ & $p=0.009^{*}$ \\
\hline Maxilla & $0,33 \mathrm{~mm} \mathrm{n}=135(\mathrm{SD} 0.53)$ range: $0.00-4.90$ & $0.61 \mathrm{~mm} \mathrm{n}=31(\mathrm{SD} 0.66)$ range $0.00-2.80$ & $p=0.008^{*}$ \\
\hline Mandible & $0,27 \mathrm{~mm} \mathrm{n}=117(\mathrm{SD} 0,58)$ range $0.00-4,20$ & $0.32 \mathrm{~mm} \mathrm{n}=34(\mathrm{SD} 0.43)$ range $0.00-1.58$ & $\mathrm{P}=0.097$ \\
\hline p value & $\mathrm{p}<0.001^{*}$ & $\mathrm{p}=0.020^{*}$ & \\
\hline
\end{tabular}

Table 6. Overview of individual peri-implant bone loss values and patient's bone loss values in smokers and nonsmokers with respect to the jaw.

* Statistically significant at 0.05 level with Mann-Whitney U-test. 


\begin{tabular}{|l|l|l|l|l|l|l|l|l|l|}
\hline & Value & $95 \% \mathrm{Cl}$ & SE & $\mathrm{p}$-value & & Value & $95 \% \mathrm{Cl}$ & $\mathrm{SE}$ & $\mathrm{p}$-value \\
\hline Intercept & -1.90 & & 0.15 & & & -1.60 & $-1.74 /-1.45$ & 0.07 & \\
\hline Maxilla & 0.83 & $0.45 / 1.20$ & 0.19 & 0.000 & & $0^{\mathrm{a}}$ & & 0 & \\
\hline Mandible & $0^{\mathrm{a}}$ & & 0 & & & -0.45 & $-0.65 /-0.24$ & & 0.000 \\
\hline Nonsmoker & -0.15 & $-0.49 / 0.18$ & 0.17 & 0.378 & & $0^{\mathrm{a}}$ & & 0 & \\
\hline Smoker & $0^{\mathrm{a}}$ & & 0 & & & 0.52 & $0.20 / 0.85$ & & 0.001 \\
\hline Maxilla * Nonsmoker & -0.37 & $-0.80 /-0.05$ & 0.22 & 0.84 & & $0^{\mathrm{a}}$ & & 0 & \\
\hline Maxilla * Smoker & $0^{\mathrm{a}}$ & & 0 & & & $0^{\mathrm{a}}$ & & 0 & \\
\hline Mandible * Nonsmoker & $0^{\mathrm{a}}$ & & 0 & & & $0^{\mathrm{a}}$ & & 0 & \\
\hline Mandible * Smoker & $0^{\mathrm{a}}$ & & 0 & & & -0.37 & $-0.80 /-0.05$ & 0.22 & 0.084 \\
\hline
\end{tabular}

Table 7. Fixed model analysis after logarithmic transformation of the bone loss data. Parameters set to zero as reference (a).

\begin{tabular}{|l|r|r|r|r|r|}
\hline & Nonsmoker & \multicolumn{1}{|l|}{ Smoker } & p-value & & \\
\hline Maxilla + Mandible & $96,50 \%$ & $89,60 \%$ & $<0.001 *$ & \\
\hline Maxilla & $96,80 \%$ & $87,80 \%$ & $<0.001 *$ & \\
\hline Mandible & $96,20 \%$ & $92,20 \%$ & $=0.083$ & \\
\hline p-value & $=0.402$ & $=0.181$ & & \\
\hline
\end{tabular}

Table 8. Overview of implant success rates in smokers and nonsmokers with respect to the jaw.

*Statistically significant at 0.05 level with the Fisher's Exact Test 